\title{
Effect of Shale Inhibitors on the Particle Size Distribution of Bentonite in Aqueous Suspensions
}

\author{
Yandong Yang ${ }^{1}$, Kesheng Rong ${ }^{1}$, Cheng $\mathrm{Ye}^{1}$, Lianyun Xue ${ }^{1}$ and Gui Wang, ${ }^{2, *}$ \\ ${ }^{1}$ Engineering and Technology Research Institute, Xinjiang Oilfield Company, Karamay 834000, P. R. China \\ ${ }^{2}$ College of Petroleum Engineering, Southwest Petroleum University, Xindu, Chendu, Sichuan 610500, P. R. China. \\ ${ }^{*}$ Corresponding author
}

\begin{abstract}
Shale inhibitor has been widely used as a cure of shale dispersion and swelling when drilling in shale formation. To make clear the effect of the interaction time, type and adding order of inhibitors on the hydration of bentonite, the particle size distribution (PSD) measurements of bentonite have been performed in this investigation. The results show that the hydration time of bentonite is quite short and the aging time has a little effect on the static hydration dispersion of bentonite. Moreover, the adding order of the different type of inhibitors has clearly effect on the hydration of bentonite. The observed results show that all the inhibitor solutions investigated, including organic salt, inorganic salt and polymeric inhibitor solutions, show obvious inhibiting ability on the hydration dispersion of bentonite. In contrast, after adding into bentonite suspensions, organic salt and inorganic salt inhibitors have little effect on the dispersion of bentonite, while the polymeric inhibitors can inhibit the hydration dispersion of bentonite effectively. It supports the idea that the salt inhibitor plays a preventive role rather than corrective role in inhibiting the bentonite dispersion.
\end{abstract}

Keywords-shale inhibitor, particle size distribution, bentonite, hydration, dispersion

\section{INTRODUCTION}

In the drilling operation, shale hydration may lead to some problems, such as thickening of drilling mud, bit balling, borehole enlargement and even oil well abandonment [1-4]. Keeping wellbore stable is one of the most significant task in achieving the success of drilling operations. Therefore, a clear understanding on the effect of inhibitors on the hydration of shale is beneficial to take measures to combat clay hydration.

In the past, much research effort has been made on the hydration of bentonite, and several means used to study the hydration of bentonite [4]. Conventionally, the rolling recovery test is used to evaluate the inhibiting ability of hydration dispersion [5]. Moreover, the filtrate loss and the linear swelling test have been used to study the influence of the shale inhibitors on the bentonite hydration swelling [4][6]. The pressure transmission test was used to study the inhibiting ability of the shale inhibitor [7]. Also, rheological property has been used to evaluate the inhibiting performance of shale inhibitors [5]. The bulk hardness test, was used to determine the hardness of the shale sample after exposure to a test fluid that contains shale inhibitor. In addition, transmission electron microscopy was used to observe the dispersed state of bentonite particles in aqueous solutions, and the sedimentation of the montmorillonite was also used to evaluate the inhibiting performance [8]. Furthermore, X-ray diffraction was used to measure the clay layer space of bentonite to evaluate the inhibiting performance of shale inhibitors [9]. However, the particle size of bentonite powder in aqueous suspension has rarely been addressed [10].

In this study, the particle size distribution of bentonite powder after the action of inhibitors are taken as the direct method to investigate the hydration dispersion of bentonite. The particle size distribution (PSD) of bentonite can reflect the microscopic disperse state of bentonite powder directly [11]. The PSD of bentonite was measured with a Laser Scattering Particle Size Analyzer. The influence of hydration time, the shale inhibitor type, and adding order of shale inhibitors on the hydration dispersion characteristics were also investigated by measuring the PSD of bentonite suspensions. Moreover, the mechanisms of the inhibitors are briefly discussed.

\section{MATERIALS AND METHODS}

\section{A. Materials}

The 4wt\% hydrated Na-MMT aqueous suspension was used as base fluid. Three kinds of common inhibitors, inorganic sail, organic salt and polymeric inhibitor were selected in this study. Inhibitor aqueous solutions were prepared with the recommended dosage of each inhibitor. The recommended dosages (wt/v) of the shale inhibitors used in this study are listed in Table 1.

TABLE I. THE RECOMMENDED DOSAGE OF SHALE INHIBITORS

\begin{tabular}{cccccc}
\hline \multirow{2}{*}{ Inhibitors } & \multicolumn{2}{c}{ Inorganic salt } & $\begin{array}{c}\text { Organic } \\
\text { salt }\end{array}$ & \multicolumn{2}{c}{ Polymeric inhibitor } \\
\cline { 2 - 6 } & $\mathbf{K C l}$ & $\mathbf{C a C l}_{2}$ & Weigh2 & $\begin{array}{c}\text { Polyamine } \\
\text { SIAT }\end{array}$ & $\begin{array}{c}\text { Polyalcohol } \\
\text { JLX-B }\end{array}$ \\
\hline $\begin{array}{c}\text { Dosage } \\
/ \%\end{array}$ & 7 & 0.5 & 30 & 2 & 2 \\
\hline
\end{tabular}

\section{B. Methods}

To investigate the effect of the adding order of shale inhibitors on the dispersion of bentonite, this study took two different adding orders. The first adding order is that adding inhibitors into base fluid, called adding order 1\#, while the second order is that adding bentonite powder into inhibitor solutions, called adding order $2 \#$ in the following text. 
After adding inhibitors and bentonite, the aqueous suspension was stirred for 30 minutes, then took a small amount of sample into the Laser Scattering Particle Size Analyzer to measure its PSD. The PSD measurement was repeated at least three times for accuracy. The PSD curves and the characteristic values, $D_{10}, D_{50}, D_{90}$, and $D_{\text {ave }}$, are adopted in this paper to present the particle size distribution of the bentonite suspensions.

\section{RESULTS AND DISCUSSION}

\section{A. Effect of Interaction Time}

In order to investigate the effect of interaction time on the dispersion of bentonite, the PSD of the bentonite suspension was tested at $0.5 \mathrm{~h}, 2 \mathrm{~h}, 8 \mathrm{~h}$, and $24 \mathrm{~h}$, respectively. The PSD curve of base fluid is shown in Fig.1. Table 2 lists the characteristic parameters of the base fluid at different time.

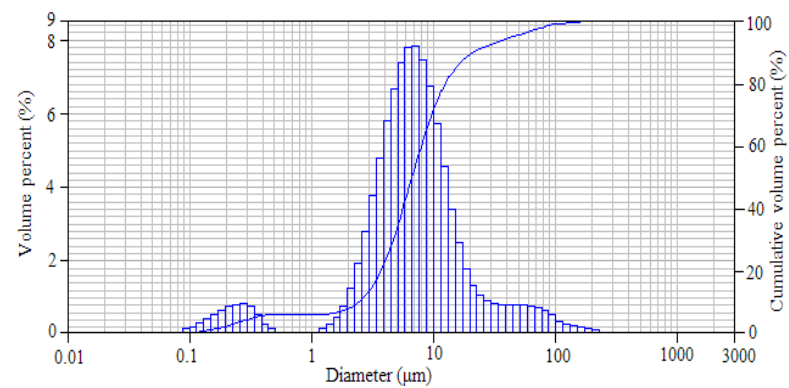

FIGURE I. PSD CURVE OF THE 4WT\% BENTONITE SUSPENSION

TABLE II. CHARACTERISTIC SIZE VALUES OF THE BASE FLUID AFTER DIFFERENT TIME

\begin{tabular}{clllc}
\hline Time/h & $\boldsymbol{D}_{\mathbf{1 0}} / \boldsymbol{\mu m}$ & $\boldsymbol{D}_{\mathbf{5 0}} / \boldsymbol{\mu m}$ & $\boldsymbol{D}_{\mathbf{9 0}} / \boldsymbol{\mu m}$ & $\boldsymbol{D}_{\text {ave }} / \boldsymbol{\mu m}$ \\
\hline 0.5 & 2.46 & 6.43 & 17.84 & 13.03 \\
2 & 2.48 & 6.79 & 21.71 & 12.25 \\
8 & 2.32 & 6.76 & 23.11 & 13.08 \\
24 & 2.49 & 6.86 & 22.52 & 12.99 \\
\hline
\end{tabular}

As can be seen from Fig.1, the PSD curve of base bentonite suspension has a wide range of size, from $0.1 \mu \mathrm{m}$ to $200 \mu \mathrm{m}$, and mainly centered around $10 \mu \mathrm{m}$. A close look at the PSD curve can obtain the characteristic granularity values, as listed in Table 2. The $D_{50}$ of the PSD is about $6.5 \mu \mathrm{m}$, which is in accordance with the report from previous research [12]. The fact that all the characteristic granularity values at different hydration time are approximate, demonstrates that the hydration dispersion process of bentonite is quite rapid.

\section{B. Effect of Inorganic Inhibitor}

Inorganic inhibitor is the earliest used shale inhibitor in the oil well drilling industry. Among the inorganic inhibitors, potassium chloride $(\mathrm{KCl})$ is the best known inhibitor for its outstanding inhibition property [7][13]. $\mathrm{CaCl}_{2}$ has also won some popularity among the researchers [14]. In this work, the effects of $\mathrm{KCl}$ and $\mathrm{CaCl}_{2}$ on the hydration dispersion of bentonite have been studied. The PSD curves of the bentonite under the action of inorganic inhibitors are shown in Fig. 2 and Fig.3.

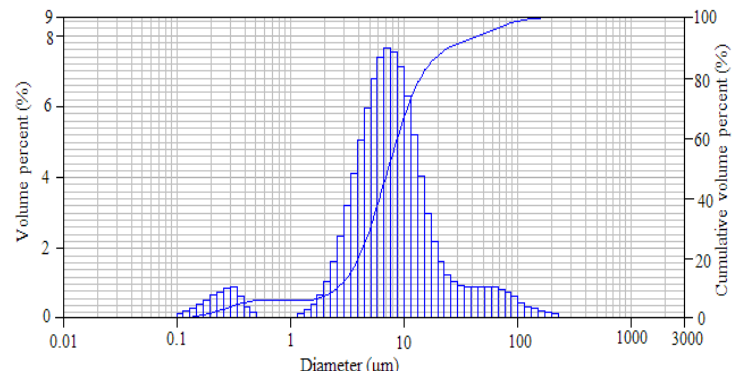

(A) FOR ADDING KCL INTO BASE FLUID.

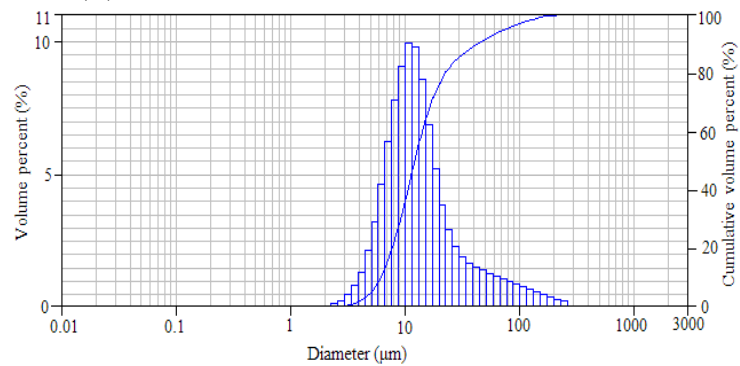

(B) FOR ADDING BENTONITE INTO KCL SOLUTION.

FIGURE II. PSD OF THE BENTONITE UNDER THE ACTION OF KCL

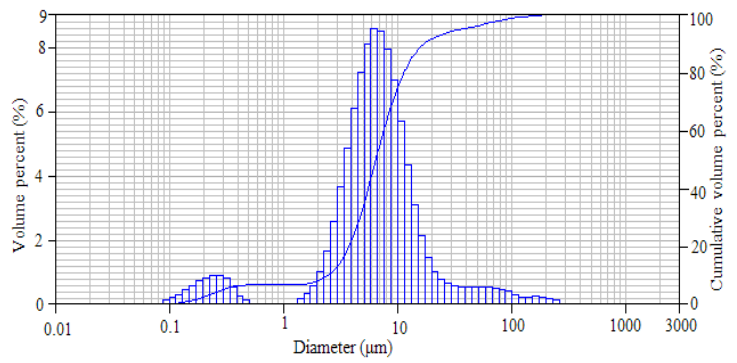

(A) FOR ADDING CACL 2 INTO BASE FLUID.

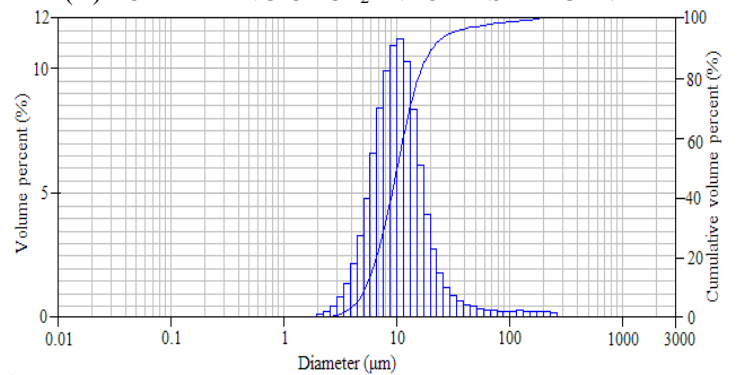

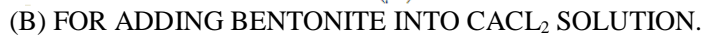

FIGURE III. PSD OF THE BENTONITE UNDER THE ACTION OF $\mathrm{CACL}_{2}$

From Figure 2(a) and Figure 3(a), it can be clearly seen that all the PSD curves are similar with that of the base fluid. However, a close comparison of Figure 2(b) and Figure 3(b) with base fluid shows that the submicron, smaller than $1 \mu \mathrm{m}$, is decreased or absent. In addition, the differential distribution curves move right. It means the content of the large size particle increases, also indicates that inorganic inhibitors solution can keep bentonite powder from hydrating. 
For a clear understand of the effect of inhibitor, the characteristic parameters of PSD are obtained and shown in Fig.4.

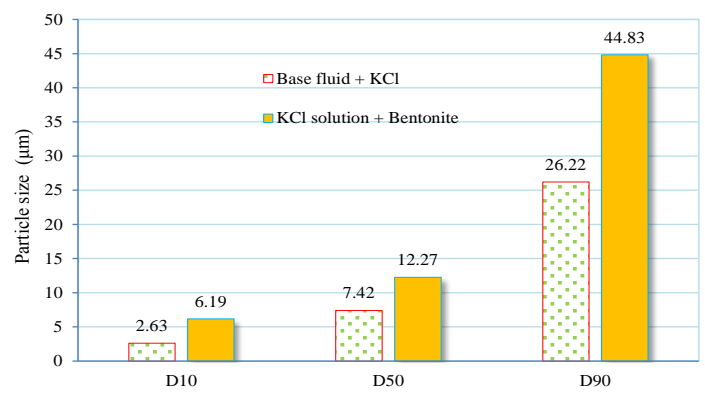

(A)

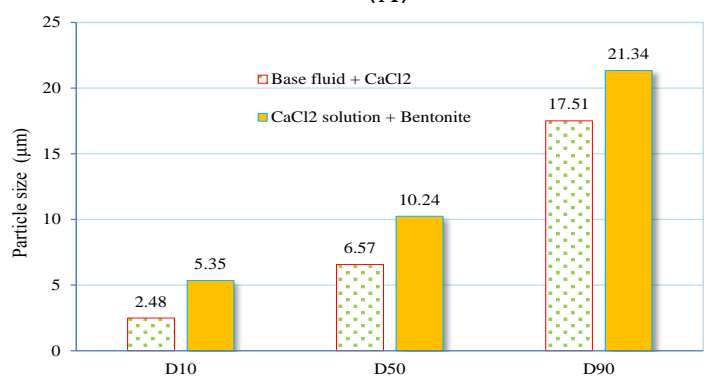

(B)

FIGURE IV. COMPARISON OF THE CHARACTERISTIC PARAMETERS OF THE PSD FOR THE BENTONITE UNDER THE ACTION OF INORGANIC INHIBITORS. (A) FOR KCL, (B) FOR $\mathrm{CACL}_{2}$

As shown in Figure 4, for the case adding inhibitor into base fluid, the bentonite keeps the dispersion state and remains hardly changed by inorganic salts. The $D_{50}$ of bentonite suspension after treated by $\mathrm{KCl}$ is $7.42 \mu \mathrm{m}$, and the average particle size $D_{\text {ave }}$ is $13.66 \mu \mathrm{m}$, which is slightly larger than the particle size of base fluid. Similarly, the $D_{50}$ and $D_{\text {ave }}$ of bentonite suspension that treated by $\mathrm{CaCl}_{2}$ are also approaching to the particle size of base fluid. However, for the adding order that adding bentonite powder into inhibitor solutions, the characteristic parameters are obviously larger than those of the base fluid. The results indicate that inorganic salts can keep the clay particle from dispersing, which is in agreement with most of the available studies [4][7]. It can be concluded that the inorganic salts play a preventive role in inhibiting bentonite hydration rather than a corrective role.

\section{Effect of Organic Salt Inhibitor}

Due to the benefits that it can reduce swelling pressure, water content and pore pressure at the same time, organic salt inhibitor has won great popularity in oil well drilling industry (Oort, 2003; Oort et al., 1994). The potassium formate (HCOOK), sodium formate (HCOONa), cesium formate (HCOOCs) and their mixture are the most common used organic salt inhibitors. This work tested the particle size distribution of bentonite under the action of an organic salt mixture inhibitor called Weigh2.
This paper presents the PSD curves and the corresponding characteristic parameters for the bentonite suspensions with the two adding orders as shown in Figure 5 through 6.

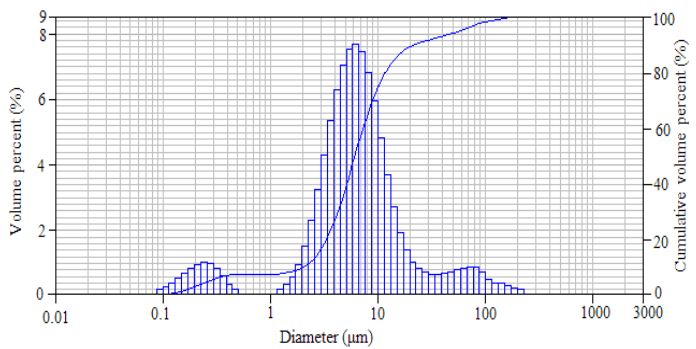

(A) FOR ADDING ORGANIC SALT INTO BASE FLUID.

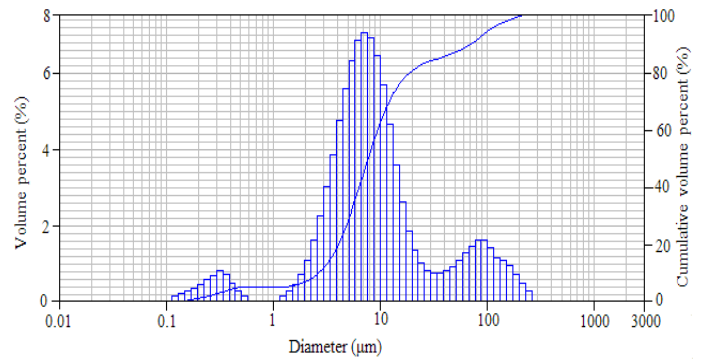

(B) FOR ADDING BENTONITE INTO ORGANIC SALT SOLUTION.

FIGURE V. PSD CURVES FOR THE BENTONITE UNDER THE ACTION OF THE ORGANIC SALT

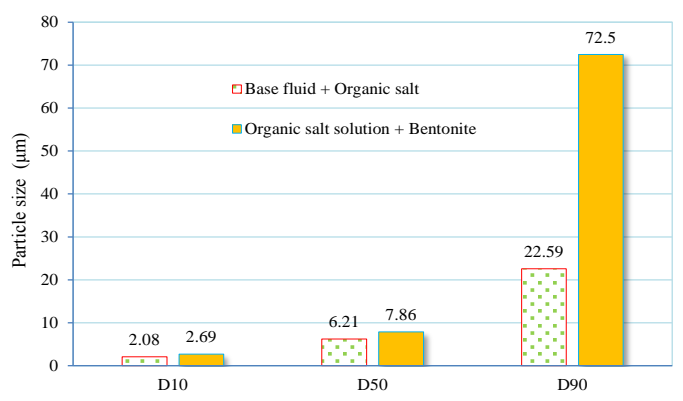

FIGURE VI. COMPARISON OF THE CHARACTERISTIC PARAMETERS OF THE PSD FOR THE BENTONITE UNDER THE ACTION OF ORGANIC SALT

As can be observed from Figure 5 through 6, after being hydrated (adding order $1 \#$ ), the bentonite the particle size remained unchanged by organic salt. In contrast, for adding bentonite powder into organic salt solution (adding order 2\#), the PSD curves and the corresponding characteristic parameters are slightly different. It can be concluded that the organic salt can only prevent bentonite from dispersing slightly, but cannot play the corrective role in hydration dispersion of bentonite.

\section{Effect of Polymeric Inhibitor}

Polyamine and polyalcohol are generally accepted overall as the best polymeric inhibitors in well drilling industry [15]. Polyamine has been extensively used as shale hydration inhibitor with its splendid inhibiting performance, and it has gained many interests and found an application [16] [17]. Polyalcohol also has been widely used in the drilling process, because they not only inhibit the swelling of clay minerals, but 
also keep the shale strength in the process of action together with inorganic salts [18].

The PSD curves for bentonite in the polymeric inhibitors solutions of Polyamine (SIAT) and Polyalcohol (JLX-B) are shown in Figure 7 and Figure 8, respectively.

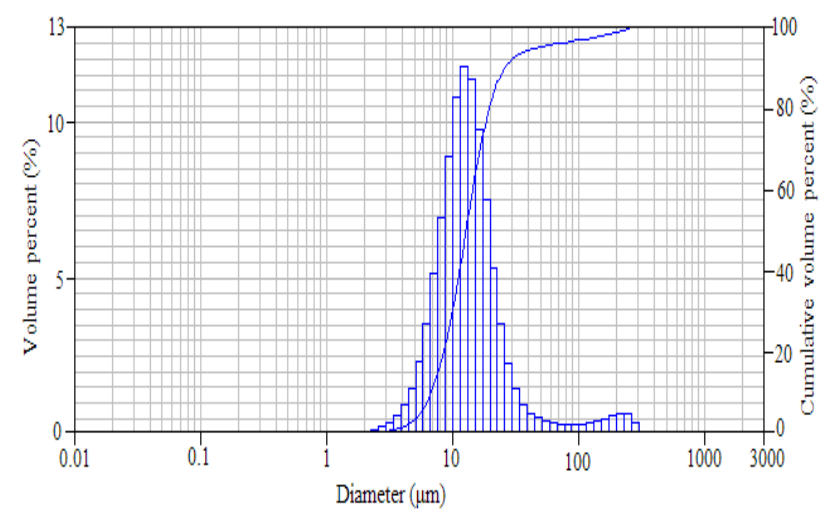

FIGURE VII. PSD CURVES FOR THE BENTONITE UNDER THE ACTION OF SIAT

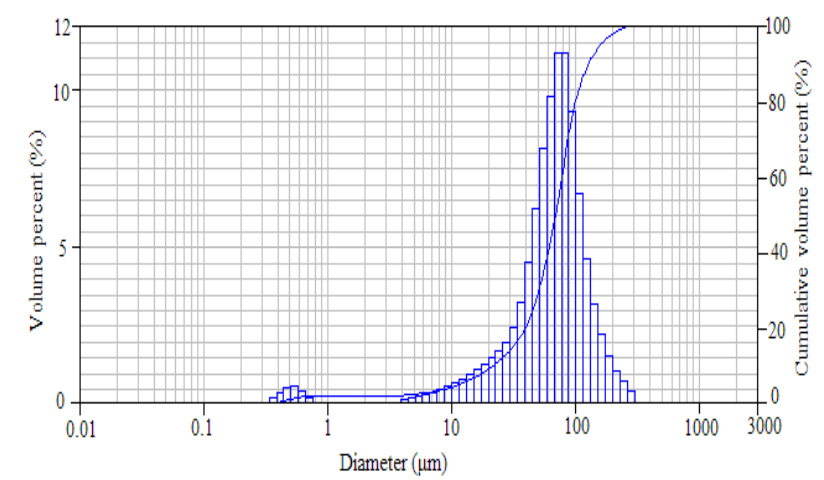

FIGURE VIII. PSD CURVES FOR THE BENTONITE UNDER THE ACTION OF JLX-B

As can be seen in Figure 5 and Figure 6, compared with the PSD of the base fluid, the crest of the PSD curves have been moving to the right, and they all almost have no submicron particle less than $1 \mu \mathrm{m}$. Therefore, the polymeric inhibitors also can prevent clay particles from dispersing.

In order to investigate the adding order effect on the bentonite dispersion, the characteristic parameters of the PSD for bentonite suspensions of both adding order $1 \#$ and adding order 2\# were measured, as shown in Figure 9.

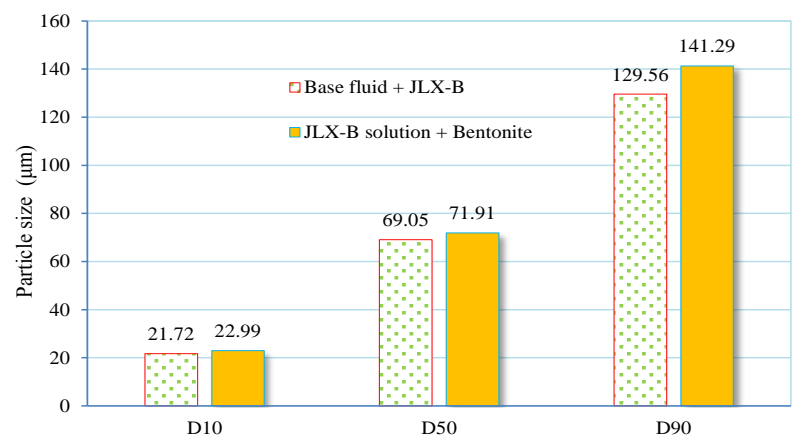

(A)

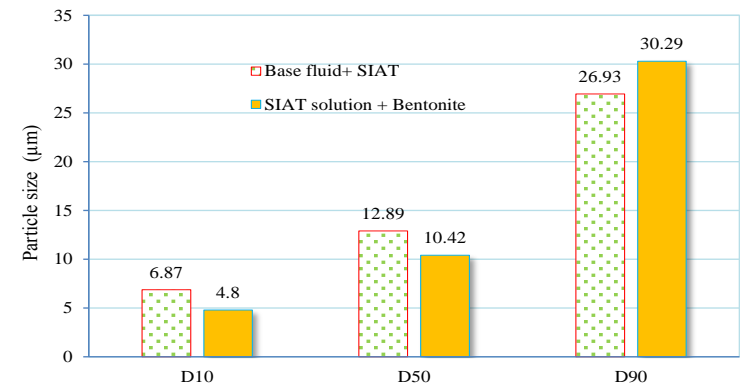

(B)

FIGURE IX. COMPARISON OF THE CHARACTERISTIC PARAMETERS OF THE PSD FOR THE BENTONITE UNDER THE ACTION OF POLYMERIC INHIBITORS. (A) FOR POLYALCOHOL JLX-B, (B) FOR POLYAMINE SIAT

As can be seen in Figure 9, the $D_{50}$ and the $D_{\text {ave }}$ of bentonite in different adding order are all larger than the corresponding characteristic parameters of the base fluid. The larger particle size indicates the hydration dispersion of bentonite can be maximally suppressed by polyalcohol. The results demonstrate that polyalcohol JLX-B exhibit superior inhibition compared to polyamine.

Another import observation is that the characteristic parameters of PSD for the different adding orders are almost identical, which suggests that the adding order has little impact on the inhibiting performance of polymeric inhibitor. Furthermore, the addition of polymeric inhibitors has a positive effect on suppressing the hydration dispersion of clay particles even the clay has been fully dispersed. The polymeric inhibitors can play both preventive and corrective role in suppressing bentonite hydration dispersion.

\section{E. Effect of Inhibitors Combination}

For the reason that the inhibitors of different type play different roles, the combination of inhibitors usually be taken into account, and have already shown greater inhibiting performance than they act alone [4]. For instance, organic inhibitors are usually applied associated with other inorganic inhibitors [19].

To check the effect of inhibitors combination on the bentonite hydration dispersion, this work selected $\mathrm{KCl}$, Weigh2 and JLX-B as the representative of inorganic salt, organic salt and polymeric inhibitors, respectively. The characteristic parameters of the PSD for the bentonite under the action of combined inhibitors are listed in Table 3.

TABLE III. CHARACTERISTIC PARAMETERS OF THE PSD FOR THE BENTONITE UNDER THE ACTION OF COMBINED INHIBITORS

\begin{tabular}{cccccc}
\hline No. & Fluid sample & $\boldsymbol{D}_{\mathbf{1 0}} / \boldsymbol{\mu m}$ & $\boldsymbol{D}_{\mathbf{5 0}} / \mathbf{\mu m}$ & $\boldsymbol{D}_{\mathbf{9 0}} / \boldsymbol{\mu m}$ & $\boldsymbol{D}_{\text {ave }} / \boldsymbol{\mu m}$ \\
\hline 1 & $\begin{array}{c}\text { Base fluid + Inhibitor } \\
\text { (KCl + Weigh2) } \\
(\text { KCl + Weigh2) }\end{array}$ & 2.32 & 6.77 & 23.10 & 13.07 \\
2 & $\begin{array}{c}\text { solution + Bentonite } \\
\text { Base fluid + Inhibitor } \\
\text { (KCl + JLX-B) }\end{array}$ & 21.10 & 12.57 & 52.87 & 24.43 \\
3 & $\begin{array}{c}\text { (KCl + JLX-B) solution } \\
\text { + Bentonite }\end{array}$ & 24.77 & 81.84 & 151.89 & 87.86 \\
4 & & & & & \\
\hline
\end{tabular}


inhibition, and filtration and rheological properties of bentonite based drilling fluids”, SPE Eastern Regional Meeting, Columbus, Ohio, USA, 2011.

[5] A. Patel, E. Stamatakis, S. Young, and J. Friedheim, "Advances in inhibitive water-based drilling fluids-Can they replace oil-based muds? ”, SPE International Symposium on Oilfield Chemistry, Houston, Texas, USA, 2007.

[6] S. Y. Liu, X. G. Mo, C. G. Zhang, D. J. Sun, and C. H. Mu, "Swelling inhibition by polyglycols in montmorillonite dispersions", J. Dispersion Sci. Technol., vol. 25, pp. 63-66, 2004.

[7] V. E. Oort, "On the physical and chemical stability of shales", J. Petr. Sci. Eng., vol. 38, pp. 213-235, 2003.

As descripted in Table 3, the PSD of hydrated bentonite cannot be changed by adding the combined inorganic salt $\mathrm{KCl}$ and organic salt Weigh2. On the contrary, the characteristic parameters of PSD for reversed adding order are larger than the corresponding parameters of $\mathrm{KCl}$ and Weigh2 acting alone, exhibiting a better inhibition. From the other data in Table 6, it can be found that the polyalcohol JLX-B plays a major role in inhibiting the dispersion of bentonite, and the adding order also exhibites a significant effect.

Furthermore, from the PSD data of different combined inhibitors, we can draw a conclusion that the combination of the polymeric inhibitor with the organic salt or the inorganic salt plays both corrective and preventive roles in suppressing bentonite dispersion.

\section{CONCLUSIONS}

The particle size distribution measurements of bentonite suspensions under the action of commonly used shale inhibitors have been carried out. The following conclusions were drawn from the experimental results.

- $\quad$ After a rapid dispersion of bentonite in water, the static aging time has little effect on the PSD of bentonite.

- All the commonly used inorganic salt, organic salt, polymeric inhibitors and their combination, can play a preventive role in bentonite hydration dispersing.

- $\quad$ Only polymeric inhibitors and the combined inhibitors with polymeric inhibitors can be taken as corrective inhibitors.

\section{ACKNOWLEDGMENT}

The authors would like to thank the financial support from the Xinjiang Daqing Major Projects funded by the China National Petroleum Corporation.

\section{REFERENCES}

[1] C. F. Lu, "A new technique for the evaluation of shale stability in the presence of polymeric drilling fluid”, SPE Production Engineering, vol. 3, pp.366-374, 1988.

[2] J.J. Sheu, and A.C. Perricone, "Design and synthesis of shale stabilizing polymers for water-based drilling fluids", SPE Annual Technical Conference and Exhibition, Houston, Texas, USA,1988

[3] R. L. Anderson, H.C. Greenwell, J.L. Suter, R.M. Jarvis, and P.V. Coveney, "Towards the design of new and improved drilling fluid additives using molecular dynamics simulations”, Ann. Braz. Acad. Sci., vol. 82, pp. 43-60, 2010.

[4] I.E.O. Onuoha, H.I. Bilgesu, and S. Ameri, "Study of drilling fluid additives and their impact on smectite inhibition, Marcellus shale
[8] L. Wang, S.Y. Liu, T. Wang, and D.J. Sun, "Effect of poly(oxypropylene) diamine adsorption on hydration and dispersion of montmorillonite particles in aqueous solution”, Colloids and Surfaces A: Physicochem. Eng. Aspects, vol. 381, pp. 41-47, 2011.

[9] M.E. Brady, B. Craster, J.M. Getliff, and P.I. Reid, "Highly inhibitive, low-salinity glycol water-base drilling fluid for shale drilling in environmentally sensitive locations", SPE International Conference on health, safety and environment in oil and gas exploration and production, Venezuela, 1998.

[10] K. Bessho, and C. Degueldre, "Generation and sedimentation of colloidal bentonite particles in water”, Applied Clay Science, vol. 43, pp. 253-259, 2009.

[11] A. Benchabane, and K. Bekkour, "Effects of anionic additives on the rheological behavior of aqueous calcium montmorillonite suspensions", Rheol. Acta., vol. 45, pp. 425-434, 2006.

[12] X.H. Meng, Y.H. Zhang, F.S. Zhou, and Q. An, "Influence of carbon ash on the rheological properties of bentonite dispersions", Applied Clay Science, vol.88-89, pp.129-133, 2014.

[13] R. K. Clark, "Applications of water-soluble polymers as shale stabilizers in drilling fluids”, Water-Soluble Polym., vol.10, pp.171-181, 1986.

[14] J. Lim, R.G. Kretser, and P.J. Scales, "Investigating the influence of total electrolyte concentration and sodium-calcium ion competition on controlled dispersion of swelling clays”, Int. J. Miner. Process., vol. 93, pp. 95-102, 2009.

[15] R. Caenn, "Drilling fluids: State of the art”, J. Petr. Sci. Eng., vol.14, pp.221-230,1996.

[16] H.Y. Zhong, Z.S. Qiu, W.A. Huang, and J. Cao, "Poly (oxypropylene)amidoamine modified bentonite as potential shale inhibitor in waterbased drilling fluids”, Applied Clay Science, vol.67-68, pp.36-43, 2012.

[17] H.Y. Zhong, Z.S. Qiu, W.A. Huang, J. Cao, F. W. Wang, and B. Q. Xie, "Inhibition comparison between polyether diamine and quaternary Sources, Part A, vol.35, pp.218-225, 2013.

[18] M.S. Aston, and G.P. Elliott, "Water-based glycol drilling muds-shale inhibition mechanisms”, European Petroleum Conference, London, U. K., 1994.

[19] L. Ghimici, and S. Dragan, "Behaviour of cationic polyelectrolytes upon binding of electrolytes: effects of polycation structure, counterions and nature of the solvent”, Colloid Polym. Sci., vol. 280, pp.130-134, 2002. a 